\title{
EFFECT OF POPULATION DYNAMICS AND LAND USE ON THE CONTRIBUTION OF SEDIMENTS TO RESERVOIRS FOR HYDROPOWER GENERATION
}

\author{
BLANCA A. BOTERO ${ }^{1}$, JUAN CAMILO PARRA ${ }^{2}$ \& MANUELA OTÁLVARO $^{1}$ \\ ${ }^{1}$ Facultad de Ingenierías, Universidad de Medellín, Colombia \\ ${ }^{2}$ Facultad de Ingenierías, Politécnico Colombiano Jaime Isaza Cadavid, ISAII, Colombia
}

\begin{abstract}
Sediment load in reservoirs causes loss of reservoir storage and reduces its usable life. There are management strategies focused in sediment removal or reducing trapping in reservoirs, and there are basin management strategies oriented to reduce sediment production and load reaching reservoirs. In a social and political moment, like the present time in Colombia, rural return migration is expected. Ex ante evaluation of strategies to reducing sediment production is required, in order to implement them previously and avoid the acceleration of the reduction of the usable life of reservoirs. This paper presents the assessment of the impact on sediment production in a basin according to different land use planning strategies, in the context of the rural population dynamics expected in the coming years in Colombia. The San Carlos River basin contributes to a reservoir for hydropower generation, which currently generates the major percentage of hydropower energy in the power generation matrix of Colombia. We implemented on the basin the TETIS model, a distributed conceptual hydrological and sediment model. This model allows to estimate sediment production, through simulation of solid discharge series at anywhere in the basin. The TETIS sedimentological sub-model was calibrated and validated using reservoir sedimentation volumes as an estimator of the total sediment transport. Different strategies and alternatives for land use were established, including lack of planning and agricultural policies. Results show an increase in the sediment production in the long term, if a policy on the adequate use of the soil is not implemented. The results allow to define the strategic zones of the basin where the efforts for the implementation of good agricultural practices, reforestation and soil conservation must be focused.
\end{abstract}

Keywords: sediment production, population dynamics, management of catchments.

\section{INTRODUCTION}

The San Carlos River basin contributes to a reservoir for hydropower generation, which currently generates $10.5 \%$ of hydropower energy in the power generation matrix of Colombia [1]. This basin presents high rates of erosion, which assure a significant production of sediment moving downstream, they consequently causing loss of reservoir storage and reducing its usable life.

For the town of San Carlos, the last decade of the past century, as well as the first of the present century, became the worst lapse of time in its history, when the violence devastated a big part of its population. People abandoned their properties, constituting a forced displacement to the big cities of the region. In a social and political moment, like the present time in Colombia, experiencing a post-conflict scenario, rural return migration is expected for the next years, in a territorial dynamic that urge to be characterized and controlled.

In the context of repopulation of the San Carlos basin, for the suitable operation of the reservoir, a question must be asked: how much the sediment rate is affected by the population return and their new land use, even in controlled or in uncontrolled conditions? It seems to be clear that the State of Colombia should assume a role of leader, in order to build a vision of future for the region and an analysis of situation for it, as well as a construction of a strategy, and a provision of a holistic and integrated plan directed to achieve this control, 
inside a framework of participation of all the social actors presented in the zone. The contribution of the hydropower company owner in this process becomes particularly relevant, especially in the decision-making structure related to the basin management. For this last, Ex ante evaluation of strategies directed towards sediment reduced-production is required, in order to implement them proactively, then avoiding the acceleration of the reduction of the usable life of reservoirs.

This paper presents an assessment of the impact of different land use planning strategies on the sediment production in the mentioned basin, in the context of the rural population dynamics expected in the coming years in Colombia. The analysis was founded over a hydrologic modelling using the sediment model TETIS (a distributed conceptual hydrological and sediment model). This model allows to estimate sediment production, through simulation of solid discharge series anywhere in the basin. The TETIS sediment sub-model was calibrated and validated using reservoir sedimentation volumes as an estimator of the total sediment transport. The use of TETIS was integrated to an original approach to stablish critical zones for repopulation based on the values of the slope and the soil erodibility factor $K$ of the Universal Soil Loss (USLE) Equation [9]. These two variables are widely relevant in the Andean Mountain Ranges. The methodology allowed to obtain the sediment rate associated to four different scenarios that reflect similar levels of repopulation control. For these scenarios, diverse strategies and alternatives for land use were established, considering lack of planning and agricultural policies. Results show an increase in the sediment production in the long term, if a policy on the adequate use of the soil is not implemented. The results also allow to define the strategic zones of the basin where the efforts for the implementation of good agricultural practices, reforestation and soil conservation must be focused.

Finally, it is important to highlight that, more than to exhibit a detail model, this research endeavor to provide a robust and general approach that will serve to both stakeholders and Colombian State to identify potential changes in sediment production associated to variations in the use of land, and consequently, to support their decisions related to sediment production and control in the broad scope of the Integrated Water Resource Management (IWRM) [3], for basins with similar attributes and problems.

\section{METHODOLOGY}

The sediment rate under different scenarios of return to the territory was obtained by implementing the TETIS hydrological model [4] in the basin. For the hydrological model calibration, discharge flow data were used in a gauging station and for the sediment sub-model calibration, the reservoir's bathymetry data were used, from which the sediment rate that the basin brings to the reservoir is estimated. With the TETIS model calibrated, a sediment rate contribution baseline is run with the current state of coverage and soils. On the other hand, a map of the most critical areas in terms of erosion is obtained, combining the map of the K parameter of the USLE equation with the slope map of the basin. Four territory occupation scenarios were established in accordance with the most critical zones with respect to erosion, from Scenario 1 without control, to Scenario 4 with control. Below, each methodology step is described in detail.

\subsection{TETIS hydrological model implementation}

In the basin, the distributed hydrological model TETIS was implemented, which is a distributed conceptual model for hydrological simulation that has a sub model that allows the simulation of solid discharge. The model has been used with satisfactory results in different 
climate scenarios, in basins with a wide range of areas and for different purposes [5], [6]. The sediment sub model calibration was carried out using the sediment contributions to the reservoir calculated in different reference studies, from the bathymetries carried out in the last ten years and considering the reservoir entrapment percentage, obtained from studies provided by the company that operates the hydropower plant.

The model requires for its implementation the construction of raster type maps, which are derived from the basin DEM, such as slopes, flow velocities that are related to the slope, flow directions and flow accumulated. In addition, the soil and coverage characteristics are necessary, such as hydraulic conductivity in the upper soil layer (in saturated conditions) Ks, hydraulic conductivity in the lower soil layer (subsoil) in saturated conditions known as percolation capacity $\mathrm{Kp}$ and the useful water content of the soil $(\mathrm{Hu})$, obtained by

$$
H u=\frac{\rho_{b} P\left(H_{c c}-H_{p m p}\right)}{100 \rho_{w}},
$$

where $\mathrm{Hu}$ is the useful water content for the horizon $(\mathrm{mm}), \rho \mathrm{b}$ is the apparent density of the dry soil $\left(\mathrm{gr} / \mathrm{cm}^{3}\right), \mathrm{P}$ is horizon thickness $(\mathrm{m})$ or the root depth in the horizon, Hcc is field capacity in percentage, Hpmp is the wilting point in percentage and $\rho \mathrm{w}$ is water density. These parameters are derived from the basin soil map, the geological units map, and the land cover map. From the soil modal profiles, using the SPAW software [7], the Ks, Hcc, Hpmp and $\rho b$ values are obtained. Hu map is obtained by combining the field capacity with the depth of the roots of each basin cover. The Kp is derived from the geologic map. In Francés et al. [8], it is possible to find more detail of these parameters and how the model works. The model has eight correction factors that allow modifying the initial parameters maps, in order to calibrate the model in a more efficient way, through the use of the Nash index, and the error in volume.

The sediment sub model allows estimating the solid discharge rate, considering the land use effects, crop practices, and soil characteristics, based on the following relationship that includes USLE parameters and discharge flow:

$$
q_{t}=23210 S_{0}^{1.66}\left(\frac{Q}{W}\right)^{2.035} \frac{K}{0.15} C P
$$

where $q_{t}$ : Unitary sediment discharge, $s_{0}$ : Slope, Q: Discharge per unit width $\mathrm{W}, \mathrm{K}$ soil erodibility factor, $\mathrm{C}$ is the cover management factor (dimensionless, ranging between 0 and 1) and $P$ is practices factor (dimensionless, ranging between 0 and 1).

The $\mathrm{K}$ value is obtained from the equation proposed by Wischmeier and Smith [2]:

$$
\mathrm{K}=\frac{2.71 \times 10^{-4} M^{1.14}(12-M . O)+4.2(b-2)+3.23(c-3)}{100},
$$

where $\mathrm{K}$ is the soil erodibility factor, $\mathrm{M}$ is the particles percentage ( $\%$ of silt $) \times(100 \%$ clay), M.O is the organic matter content (\%), b is the soil structure (between $1-4$ ) and c is soil permeability (between 1-6), both given by Wischmeier and Smith [2].

Factor $\mathrm{C}$ in eqn (2) is the cover-management factor, which is the ratio of soil loss from an area with specified cover and managements to soil loss from an identical area in tilled continuous flow [11]. It is one of the most influences factors in the erosive model, as the vegetal cover reduces the rain energy at the moment of the interception and prevents it from falling directly to the ground, as well as controlling the speed of the runoff water. The values of $\mathrm{C}$ are small when the soil is protected from the rainwater impact and the surface runoff action, and vice versa; ergo, the higher the value of $\mathrm{C}$, the lower the soil coverage, that is, there is less protection. The determination of $\mathrm{C}$ is made from tabulated values depending on 
whether they are agricultural crops or forest vegetation [2]. In this article, tabulated $\mathrm{C}$ values were used for the different coverages, according to preliminary studies in the basin and in similar regions (see Table 1).

Table 1: Factors $\mathrm{C}$ and $\mathrm{P}$ for land covers adopted from preliminary studies of the basin.

\begin{tabular}{|l|c|c|}
\hline Land Cover & $\mathrm{C}$ & $\mathrm{P}$ \\
\hline Mosaic of crops, pastures and natural zones & 0.394 & 0.1 \\
\hline Open forest & 0.002 & 0.7 \\
\hline Pastures & 0.11 & 0.7 \\
\hline Secondary vegetation or in transition & 0.002 & 0.7 \\
\hline Riparan Forest & 0.002 & 0.7 \\
\hline Scrubland & 0.002 & 0.7 \\
\hline Mosaic of de pastures with natural zones & 0.11 & 0.7 \\
\hline Grasslands, pastures and herbaceous vegetation & 0.11 & 0.7 \\
\hline Fragmented forest & 0.002 & 0.7 \\
\hline Dense forest & 0.002 & 0.1 \\
\hline Mosaic of pastures and crops & 0.11 & 0.7 \\
\hline Continuous urban texture & 0 & 0.4 \\
\hline Artificial water bodies & 0.5 & 0.7 \\
\hline Mosaic of crops with natural zones & 0.394 & 0.1 \\
\hline Urban settlement & 0 & 0.4 \\
\hline Hydraulic constructions & 0 & 0.4 \\
\hline
\end{tabular}

Factor $\mathrm{P}$ in eqn (2), is the soil-loss ratio with a specific support practice to the corresponding soil loss with up and down slope tillage [10]. The values P-factor ranges from 0 to 1 , in which the highest value is assigned to areas with no conservation practices (deciduous forest); the minimum values correspond to built-up-land and plantation area with strip and contour cropping. The lower the $\mathrm{P}$ value, the more effective the conservation practices [11]. In this paper, tabulated $\mathrm{P}$ values were used for the different coverages, according to preliminary studies in the basin and in similar regions.

In the sediment production sub-model, the calculated transport capacity is first used to propagate the sediments downstream, by size fraction according to the percentage present in suspension and as bed material. Then, if there is still transport capacity, the soil is eroded proportionally to the percentage of the corresponding size fraction of parent material [8]. This material is taken into account in the TETIS model through the sand percentage maps, silt percentage and clay percentage, obtained from the basin soil map.

The simulation performed is continuous on a daily scale, and therefore potential evapotranspiration data are required. The latter is obtained from temperature data of a station located on the basin, using the Thornthwaite equation. The model uses a crop factor to estimate the real evapotranspiration from the potential and the coverage type.

\subsection{Critical zones for erodibility according to slope and $\mathrm{K}$ ranges}

From the map of the parameter $\mathrm{K}$, reclassified from 1 to 4 and from the slope also reclassified from 1 to 5 according to the matrix shown in Table 2, a map for critical zones for erodibility is obtained, which indicates with a numerical value the most critical erosion areas and slope in the basin, 9 being the most critical places for repopulation, with the highest slopes and the highest erodibility. 
Table 2: Values for critical zones according to slope and $\mathrm{K}$ ranges.

\begin{tabular}{|l|c|c|c|c|c|}
\hline & K range & $<0.11$ & $0.11-0.15$ & $0.15-0.2$ & $0.2-0.25$ \\
\hline Slope range [\%] & & 1 & 2 & 3 & 4 \\
\hline $0-12$ & 1 & 2 & 3 & 4 & 5 \\
\hline $12-25$ & 2 & 3 & 4 & 5 & 6 \\
\hline $25-50$ & 3 & 4 & 5 & 6 & 7 \\
\hline $50-75$ & 4 & 5 & 6 & 7 & 8 \\
\hline$>75$ & 5 & 6 & 7 & 8 & 9 \\
\hline
\end{tabular}

\subsection{Scenarios for land cover change after repopulation}

Four scenarios of land cover change after repopulation were built. Scenario 1 is the population return to uncontrolled areas: The forest zones in areas $6,7,8,9$ of the critical zones for erodibility map are converted to crop areas, this implies a decrease in the Hu parameter of the model, because of the depth of the roots of the forest $(1.5 \mathrm{~m})$ is greater than that of the crops $(0.8 \mathrm{~m})$. Parameter $\mathrm{C}$ increases from 0.002 to 0.394 and without practices for cropping, that is, Factor P remains at a value of 0.5 . Scenario 2 is the population return to the areas with control over the forest areas in category 9: Forest areas in category 6, 7, 8 are converted to crop areas. Hu and $\mathrm{C}$ parameters changes in the same way as in Scenario 1 and the factor $\mathrm{P}$ remains at 0.5 . Scenario 3 is the same population return established in Scenario 2, but implementing control over cropping practices, changing the $\mathrm{P}$ factor to 0.1 . Finally, Scenario 4 is the population return, preventing the occupation of forest areas in categories 8 and 9. Only areas of forest in categories 6 and 7 are converted into crop areas. The values of $\mathrm{Hu}$ and $\mathrm{C}$ in these categories change in the same way as in the previous scenarios and best practices for cropping are established, with a value of factor $\mathrm{P}$ of 0.1

\section{STUDY BASIN AND DATA DESCRIPTION}

The Basin of San Carlos is located in the Department of Antioquia (Colombia), in the Andean mountain range. It covers an area of $284.32 \mathrm{~km}^{2}$ and drain its waters to a reservoir for hydropower purposes. The reservoir is conformed mainly for contributions of the rivers San Carlos and Guatape. The annual mean precipitation is $3700 \mathrm{~mm} / \mathrm{year}$. The maps of geomorphological parameters for the model TETIS are derived from a DEM (ASTER Global Digital Elevation Model Version 2) resized to a resolution of $100 \mathrm{~m} \times 100 \mathrm{~m}$ and the parameters related to soil characteristics, explained in a prior section, are derived from the map of soil and of geological units of the basin, and from the map of land covers following the Corine and Land Cover Methodology adapted to Colombia and updated by state entities in the 2013-2014 period [11]. Data of precipitation and discharge are for the 2014-2015 period. With this information, a base line of sediment production in the basin is defined, over which different repopulation scenarios for the territory are modelled. Land covers in the basin are shown in Table 1: 40\% of the basin area is forest distributed in dense, open, fragmented and riparian; $20 \%$ are zones covered by pastures in the categories of pastures, grasslands, pastures and herbaceous vegetation; 8\% corresponds to crops and mixing of crops with pastures and natural zones; $21 \%$ of the basin surface is covered by secondary vegetation or in transition and Scrubland and just $1 \%$ corresponds to urban continuous and discontinuous settlement. The other $10 \%$ of the basin is distributed in the remaining categories. There exists a large zone of forest around the reservoir, corresponding to the owner company protected area, and the rest of forest, secondary forest vegetation and scrubs are dispersed over the basin, with some predominance to be located near the border line, in the zone with larger 
slopes. The crops are located in the middle and upper part of the basin. The average slope is $33 \%$, with values of 75 to $190 \%$ located near the border line of the basin, in the middle and upper part of it.

According to the San Carlos 2016-2019 Development Plan [12], the municipality has been presenting a growing repopulation dynamics, for which obtaining a consistent and reliable census, needed to support decisions about new urban and rural housing, is hard task. Even so, it is known that at least 2000 homes were abandoned between 1998 and 2007 due to the armed conflict, and also, that the families that have returned to the town, have found their houses and lands in a deplorable state, demanding this to rebuilding them again.

Overcrowding in some areas becomes evident the necessity of a detailed study that allow to stablish the availability of lots and the definition of expansion zones regulated by the Municipality's Territorial Ordering Scheme. According to the Colombian Beneficiary of Social Programs System SISBEN, in 2015 in San Carlos [12] there existed 4970 homes, from which 2595 were urban and 2375 rural (634 in population cores and 1741 dispersed in rural zones). As the qualitative housing deficit for 2015 was acknowledged in 30.8\% [12], a repopulation process located in rural zones is highly probable to occur in the coming years.

The Colombian State recognize the need to integrally repair the victims of the conflict. This repair implies not only a monetary compensation and goods restitution, but also an accompaniment in reference to a variety of aspects, inside of which the good practices to use the lands are included. The individual and collective repair processes also require identifying the lands legally subject to be occupied by the population that will return in condition of victims, and this task, for its own nature, can be not only difficult, but expensive in terms of time and resources. It is expected that not less than 8.000 persons were victims of the armed conflict in San Carlos. According to the Citizen Rights Protection Brief [12], only in 2005, 1621 farmers, 1681 housewives and 2129 children and young persons arrived in Medellin, one of the three largest cities in the country. None of them found suitable spaces to integrate their lives socially, culturally and economically in the city. Following the statistical data provided by ILSA [13] in the act of declaring the state of emergency, the Municipality of San Carlos presented the projection of repopulation in two stages, with a whole amount of native persons to be returned to their lands of 5000 people. These two stages can be summarized in Fig. 1.

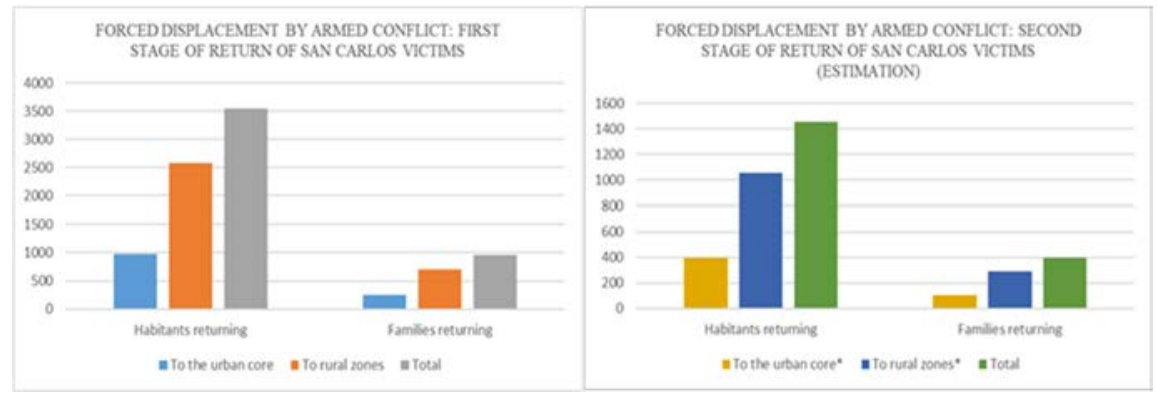

Figure 1: Population in condition of victims of the armed conflict expected to return to san.

For the first stage, the data to build the figure was entirely declared by the San Carlos Town Hall. These data can be found in ILSA [13]. For the second stage, the data in the figure is an estimation based on the difference from the total of habitants expected to be returned to the town and using the percentages of the urban and rural portion of the first stage. 
Both the amount of people returning to the Municipality and the potential use of the land that these persons will do, broadly justify all the technical efforts - of which this research is a part - to understand the effects of the possible scenarios, and consequently, the measures of management over the basin that should be adopted.

\section{RESULTS AND DISCUSSION}

Flow Discharge calibration is performed for the year 2015, using the series of daily discharge in a gauge station located in the middle part of the basin, with a Nash Index of 0.521 and a volume error of $0.212 \%$. Validation of the model is performed for the year 2014 , for which the Nash Index is equal to 0.42 and the error in volume is $-21.937 \%$. Simulation lapse covers the periods of calibration and validation and encompass until 2017 in an effort to obtain more robust results according to the provided sediment rate. Solid discharge was calibrated according to the annual rate of sediment contribution reported in studies of the hydropower company owner, based on comparing of different bathymetry measurements among years 2008 and 2015. The percentage of trapping was also reported by the company. The resultant rate of production of the model for the current condition results in a value of $0.75 \mathrm{Mm}^{3} /$ year. This value has been validated by comparing with other studies over the same basin, in which the sediment contribution rate has also been estimated. According to Hermelin [14] this rate has an associated value of $0.88 \mathrm{Mm}^{3} /$ year, while other studies from the company declares a value of $0.72 \mathrm{Mm}^{3} /$ year.

The factors $\mathrm{P}$ and $\mathrm{C}$ have been obtained from assigning the values shown in Table 1 to each of the covers in the basin. In the current conditions, low values of $\mathrm{C}$ are predominant, due to the high percentage of forest, scrubs and secondary vegetation of the basin. The last also implies high values of $P$. The map of $K$ (see Fig. 2) locates the parts with more susceptibility to erodibility in the middle and upper zones of the basin, alternated with some areas with low values of $\mathrm{K}$.

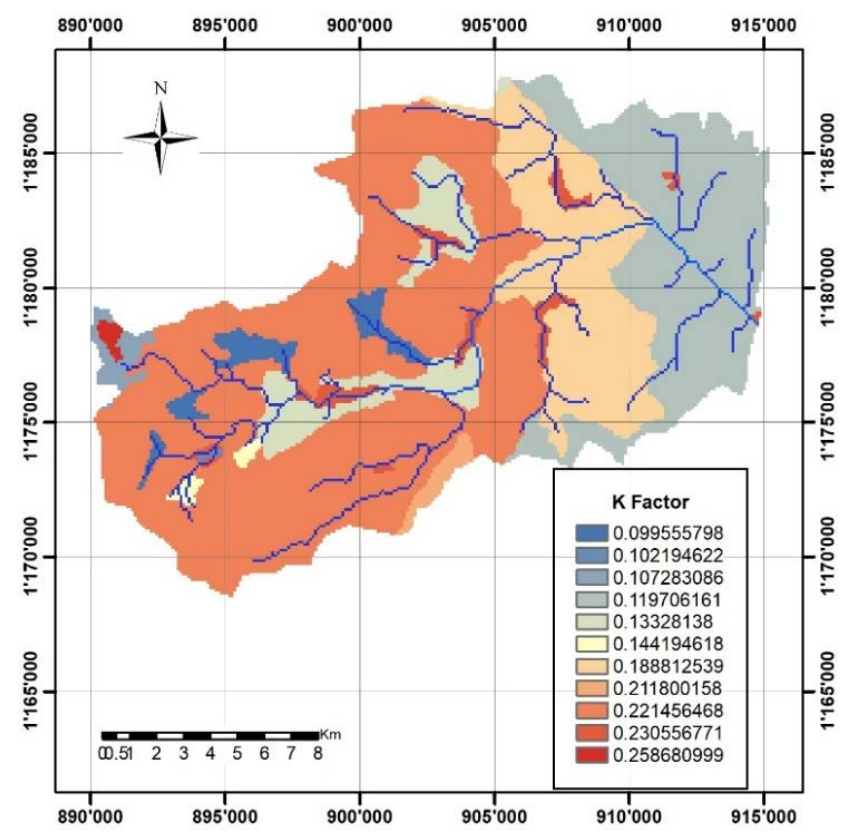

Figure 2: $\mathrm{K}$ factor. 
The map of critical zones for erodibility (see Fig. 3) intensifies those of high values of K, located in the parts with higher values of slopes, near the border in the north and the west of the basin. The effect of combining de factor $\mathrm{K}$ with the variable slope is that high values of $\mathrm{K}$ can be disaggregated in function of the slope, this implying a more real scenario for the critical condition.

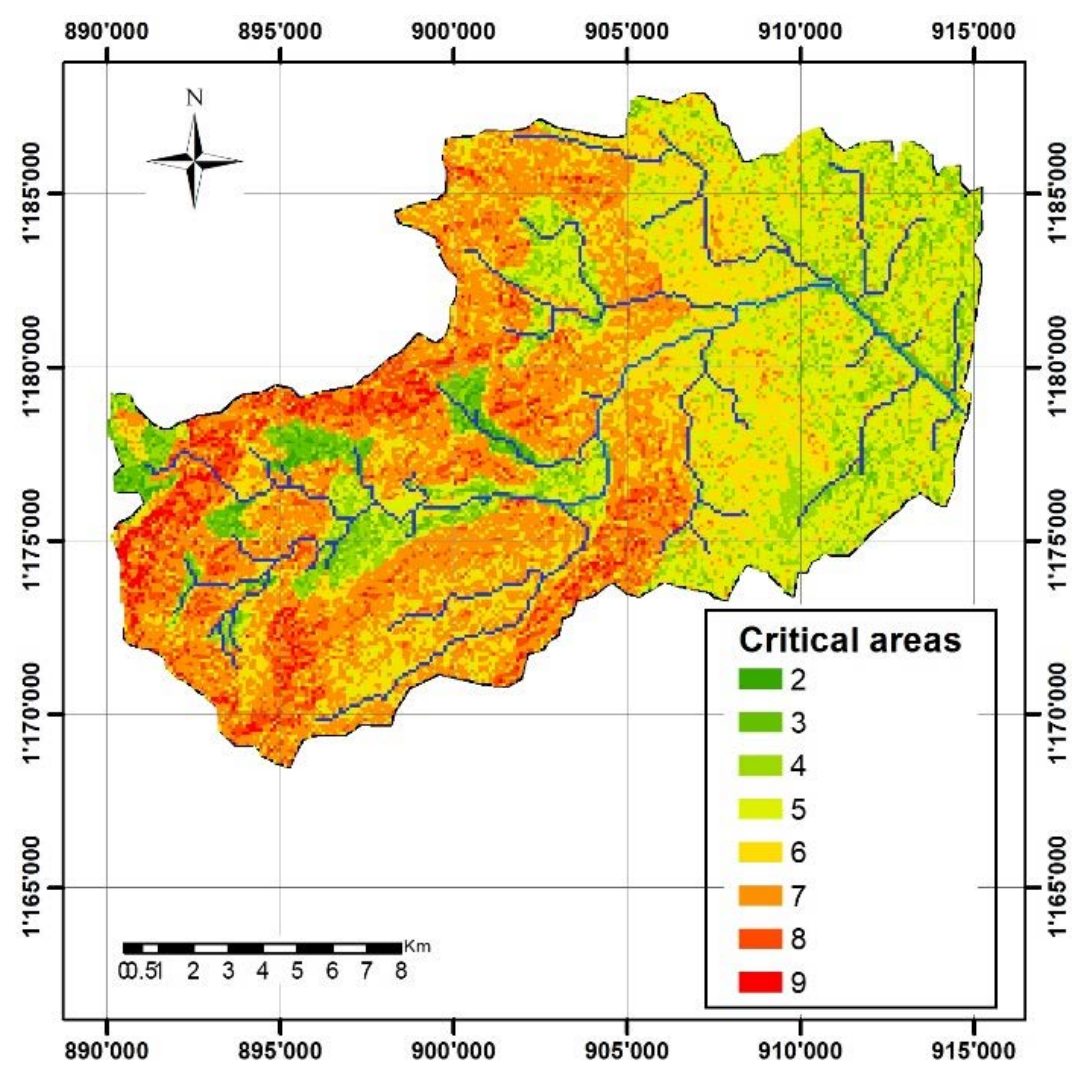

Figure 3: Critical areas according to slope and $\mathrm{K}$ ranges.

In the first scenario, $61.99 \mathrm{~km}^{2}(21.9 \%$ of the basin area) of forest cover is transformed in crops. Scenarios 2 and 3, since they did not consider the critical zones associated to a value of 9 , transform $59.6 \mathrm{~km}^{2}$ of forest to crops, which corresponds to a $21.1 \%$ of the total area.

Finally, for Scenario 4, the critical areas 8 and 9 are considered to be objects to more control, and consequently only the $18.1 \%$ of the area is transformed from forest to crops. As it was described in the Methodology section, changing the land cover from forest to crop implies a change in the parameter $\mathrm{Hu}$, and also in the factors $\mathrm{C}$ and $\mathrm{P}$.

The change in the scenarios that represents the biggest effect over the results of the rate of sediment contribution is the factor P. As it can be observed in Fig. 4, in the transition from forest to crop among the worst (1) scenario and the more positive (4) scenario, this value diminishes, also reducing in a direct way the flow of solids that is produced in each cell simulated by the model. 


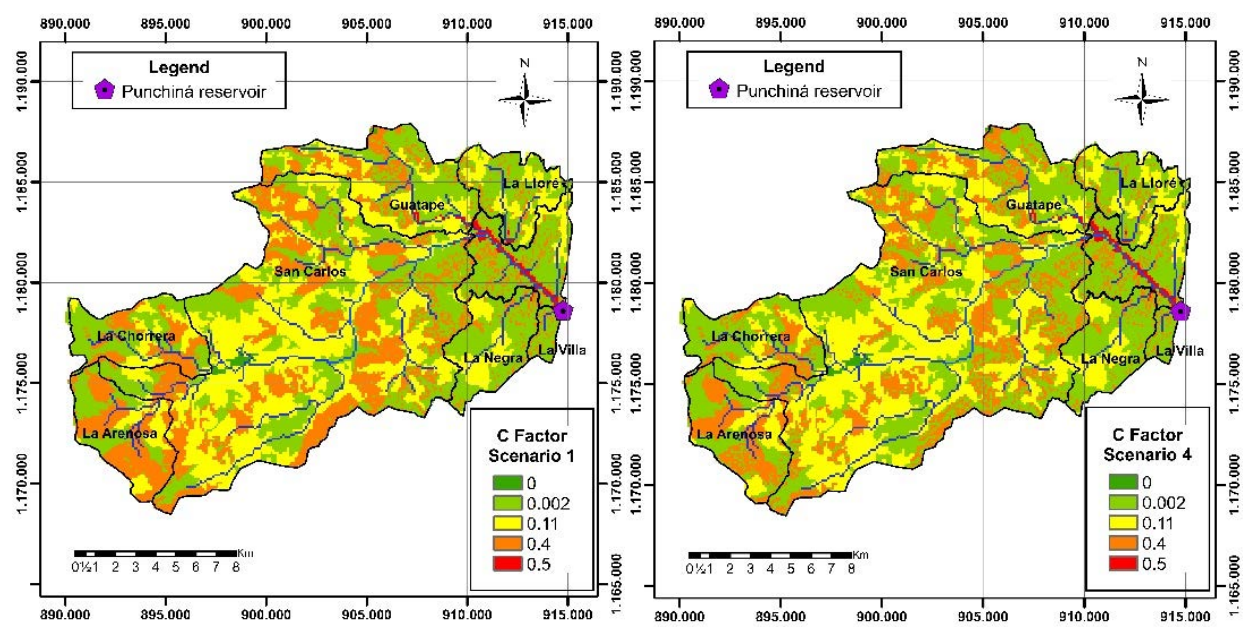

(a)
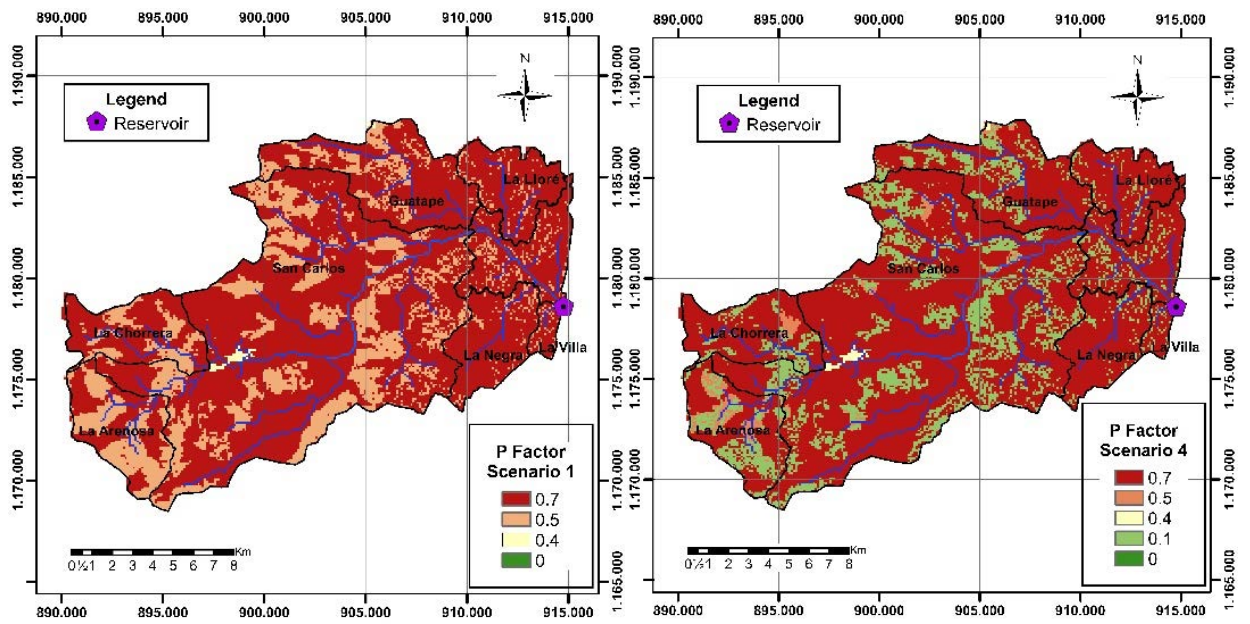

(b)

Figure 4: Factor C and P for extreme scenarios: unfavorable, favorable. (a) Factor C, Scenario 1 (left) and Scenario 2 (right); (b) Factor P, Scenario 1 (left) and Scenario 4 (right).

The result for all the four repopulation scenarios is an increment on the sediment production rate with respect to the current rate (see Table 3). The rises of $177.7 \%$ and $150.7 \%$ over the current rate are explained for the fact of changing forest for crops without implementing good practices for cropping. This result warns about the strong control that the Colombian State must apply, and similarly, about the initiatives that the basin stakeholders must carry out, in order to achieve an integrated management and to emit regulation standards directed to protect the areas located in the critical zones 8 and 9. However, the most abrupt change is evidenced among Scenarios 2 and 3, where the only difference between both scenarios consists in implementing best practices for cropping. More detailed results for 
Scenario 3 can be produced if a more precise way - considering practices subject to be implemented in the basin - to calculate the value of $\mathrm{P}$ is adopted. Nonetheless, this big reduction in the rate of sediment contribution should capture the attention of the State and the stakeholders, on the need of taking ex ante restraints, in order to prevent significant contributions to the reservoir. The difference between Scenarios 3 and 4 is small, because the forest area in level 7 corresponds only to a $3 \%$ of the total area.

Table 3: Sediment production for different scenarios of repopulation.

\begin{tabular}{|l|c|c|}
\hline Scenario & $\begin{array}{c}\text { Sediment production rate (millions of } \\
\mathrm{m}^{3} / \text { year) }\end{array}$ & \% of variation \\
\hline Original & 0.756 & - \\
\hline 1 & 2.100 & 177.7 \\
\hline 2 & 1.896 & 150.7 \\
\hline 3 & 0.774 & 2.4 \\
\hline 4 & 0.771 & 2.0 \\
\hline
\end{tabular}

According to the Colombian National Water Study [15], in the process of characterization of the sediment production due to water, water erosion in hillsides is predominantly influenced by the power of the flow and the resistance to the erosion. The first factor depends on topography and climate, while the second factor depends on the land cover and the properties of the soils [15]. As the land cover has been considered in the present research as a variable of every possible scenario, the influence of the topography has been denoted by the variations in the slope, which is highly representative of the changes in topography over de Andean Mountain range. The influence of climate is explicit considered by the conceptual hydrological and sediment model TETIS, used in this research. The resistance to the erosion was considered in the present study by means of the soil erodibility factor K, and by other variables that describe the composition and texture of the soil. This approach can be complemented in the future by adding new variables to the analysis in order to stablish the critical zones for repopulation, or even more, by considering a more detailed spatial variability of climate than those made by TETIS. For this approach, a land cover based on crops was adopted as a hypothesis for the modelling of sediment production. This is technically well supported by the tendency for rural scenarios of post-conflict, where repopulation is composed of farmers. Of course, the consequence of considering other types of land covers, as pastures or wood plantations, should be reflected in substantial changes in the values of $\mathrm{C}$ and $\mathrm{P}$. As well as the type of land cover to be predominant as the repopulation takes part, the exact amount of persons to come back to their lands is unknown to the present. This quantity, joined to the extension of every type of land cover derived from the repopulation, must be integrated to a more detailed modelling in the future, so the final results can be used in a decision support system of small scale.

\section{CONCLUSIONS}

In this paper, an exercise of hydrological modelling for an Andean basin is proposed, under four possible scenarios of territorial occupation, according to the population dynamics expected for the next years of the post-conflict process in Colombia. In a successful way, the influence of repopulation in zones where the land cover is currently forest, over the sediment production rate, was assessed in a basin that contributes to one of the reservoirs for hydropower purposes more important in the hydroelectric matrix of Colombia. In detail, it 
was found that the sediment production rate in the basin is much more sensible to implementing best practices of cropping, than to the change of land cover. Under all the scenarios of repopulation, the sediment production rate grows with respect to the original rate for the years 2014-2015. The change from forest to crops in highly critical zones, triples the current sediment rate, if there are not any best practices of cropping introduced. When best practices are considered in the model sediment production rate increases only $2 \%$ with respect to the original value.

This research provides a robust and general approach that will serve to both stakeholders in the basin and Colombian State to identify potential changes in sediment production associated to variations in the use of land, and consequently, to support their decisions related to sediment production and control in the broad scope of the IWRM for basins with similar attributes and problems.

The achieved results evidence the relevance of the role of the Colombian State, its responsibility and potential capacity of control over the repopulation process and specifically, over the use of the land (type of use and best practices). Further than that, it is clear that a high level of technical basin management is crucial to assure, not only the future operation and use of the hydropower reservoir of the study case, but to preserve the basic parameters of the ecosystems that integrate the basin. In the same context, the role of other stakeholders, primarily the hydropower owner, and the territorial environmental authority, become decisive to reach and preserve a proactive basin management level. Finally, the work shown in this paper is suggested to be part of a set of tools that can be integrated in a multi-criteria decision support framework for the use local and regional authorities.

\section{ACKNOWLEDGEMENTS}

Thanks are due to the student Sebastián Vargas from the civil engineering program of the University of Medellín, who supported maps building. Funding for this research are due to the Colombian state entity of science - Colciencias, the University of Medellín, and an energy firm whose name is confidential. Research contract FP44842-034-2016.

\section{REFERENCES}

[1] Capacidad Instalada en Colombia, Asociación Colombiana de Generadores de Energía Eléctrica (ACOLGEN). www.acolgen.org.co/. Accessed on: 23 Jun. 2019.

[2] Wischmeier, W.C. \& Smith, D.D., Predicting rainfall erosion losses: A guide to conservation planning. Agricultural Handbook, No. 537, US Department of Agriculture: Washington, DC, 1978.

[3] CAPNET UNDP, Cap-Net. Integrated Water Resources Management Plans. Training manual and operational guide CAPNET, Global Water Partnership (GWP) and UNDP, 2005.

[4] IIAMA, Modelo de simulación hidrológica e hidráulica de tipo distribuido físicamente basado y orientado a cuencas de montaña, 2019.

www.iiama.upv.es/iiama/es/transferencia/software/tetis-e.

[5] Francés, F., Vélez, J.I. \& Vélez, J.J., Split-parameter structure for the automatic calibration of distributed hydrological models. Journal of Hydrology, 332(1), pp. 226240, 2007.

[6] Bussi, et al., Impacts of climate change, land-use change and phosphorus reduction on phytoplankton in the River Thames (UK). Science of the Total Environment, pp. 15071519, 2016.

[7] Saxton, E., SPAW software, 2006. 
[8] Francés, F., Vélez, U., Múnera, J.C., Medici, C. \& Bussi, G., Descripción del Modelo Conceptual Distribuido de Simulación Hidrológica TETIS V.8, Universidad Pontificia de Valencia, pp. 1-86, 2012.

[9] Renard, K.G., Foster, G.R., Weesies, G.A., McCool, D.K. \& Yoder, D.C., Predicting soil erosion by water: A guide to conservation planning with the revised universal soil loss equation (RUSLE). Agriculture Handbook, vol. 703, US Department of Agriculture: Washington, DC, pp. 1-251, 1997.

[10] Prasannakumar, V., Vijith, H., Abinod, S. \& Geetha, N., Estimation of soil erosion risk within a small mountainous sub-watershed in Kerala, India, using Revised Universal Soil Loss Equation and geo-information technology. Geoscience Frontiers, 3(2), pp. 209-215, 2012.

[11] IGAC-IDEAM, Mapa de Coberturas de la Tierra Metodología CORINE Land Cover Adaptado para Colombia, Perido (2010-2012) 2014. Instituto de Hidrología Meteorología y Estudios Ambientales (IDEAM) and Actualizado por el Instituto geográfico Agustí Codazi (IGAC), Columbia, 2015.

[12] San Carlos Town Hall, Plan de Desarrollo de San Carlos "Trabajando por el Desarrollo Social". Alcaldía de San Carlos, 2016.

[13] Instituto Latinoamericano para una Sociedad y un Derecho Alternativos (ILSA), Desplazamiento forzado y retorno en San Carlos. Antioquia: una comunidad que regresa hacia el confinamiento, 2009.

[14] Hermelin, M., Desastres de Origen Natural en Colombia 1979-2004, EAFIT: Medellín, 2005.

[15] Instituto De Hidrología, Meteorología y estudios ambientales 2018. Reporte de Avance del Estudio Nacional del Agua, 2018. 